Proceedings

\title{
Ergosterol and Amino Acids Contents of Culinary-Medicinal Shiitake from Various Culture Conditions ${ }^{\dagger}$
}

\author{
Ibrahima Diallo 1,2,3,5, Sylvie Morel 1,2, Manon Vitou 1,2, Alain Michel ${ }^{3,4}$, Sylvie Rapior 1,2, Lonsény Traoré 5 , \\ Patrick Poucheret 3,4 and Françoise Fons ${ }^{1,2, *}$
}

Citation: Diallo, I.; Morel, S.; Vitou, M.; Michel, A.; Rapior, S.; Traoré, L.; Poucheret, P.; Fons, F. Ergosterol and Amino Acids Contents of Culinary-Medicinal Shiitake from Various Culture Conditions. Proceedings 2021, 70, 78. https:// doi.org/10.3390/foods_2020-07702

Published: 10 November 2020

Publisher's Note: MDPI stays neutral with regard to jurisdictional claims in published maps and institutional affiliations.

\section{Copyright: $\odot 2020$ by the authors.}

Licensee MDPI, Basel, Switzerland. This article is an open access article distributed under the terms and conditions of the Creative Commons Attribution (CC BY) license (http://creativecommons.org/licenses/by/4.0/).
1 Equipe Substances Naturelles et Médiations Chimiques, CEFE, Univ Montpellier, CNRS, EPHE, IRD, Univ Paul Valéry Montpellier 3, 15 avenue Charles Flahault, BP 1491, 34093 Montpellier cedex 05, France; mougnal13@gmail.com (I.D.); sylvie.morel@umontpellier.fr (S.M.); manon.vitou@umontpellier.fr (M.V.); sylvie.rapior@umontpellier.fr (S.R.)

2 Laboratoire de Botanique, Phytochimie et Mycologie, UFR des Sciences Pharmaceutiques et Biologiques, 15 avenue Charles Flahault, BP 1491, 34093 Montpellier cedex 05, France

3 Equipe Effets Santé des Aaliments et des Bioactifs Naturels, UMR Qualisud, CIRAD, Université de Montpellier, 15 avenue Charles Flahault, BP 1491, 34093 Montpellier cedex 05, France; alain.michel@umontpellier.fr (A.M.); patrick.poucheret@umontpellier.fr (P.P.)

4 Laboratoire de Pharmacologie et Physiopathologie Expérimentale, UFR des Sciences Pharmaceutiques et Biologiques, 15 avenue Charles Flahault, BP 1491, 34093 Montpellier cedex 05, France

5 Laboratoire de Technologie Alimentaire du Département de Génie Chimique, Université Gamal Abdel Nasser de Conakry, BP : 1147 Conakry-Guinée; louncenytraore8@gmail.com

* Correspondence: francoise.fons@umontpellier.fr; Tel.: +33-(0)-411759660

+ Presented at the 1st International Electronic Conference on Food Science and Functional Foods, 10-25 November 2020; Available online: https://foods_2020.sciforum.net/.

\begin{abstract}
Lentinus edodes (shiitake) is an edible mushroom cultivated and marketed due to its nutritional and medicinal values. L. edodes is appreciated for its unique fragrant taste and its high dietetic potential. Its bioactive molecules explain its interest as medicinal mushroom. This mushroom can be grown using various substrates and culture conditions. Thus, our work focused on the comparison of chemical constituents (i.e., amino acids and ergosterol) of L. edodes fruit bodies cultivated in organic or nonorganic growing conditions in the French region of Occitanie. Sequential extraction was performed on freeze-dried fungal materials. Quantitative evaluation of amino acids was done using high performance thin layer chromatography. Assay of ergosterol was carried out using high performance liquid chromatography. For both ergosterol and amino acids, differences were highlighted between extracts (depending on the nature of the solvents) and between growing conditions (organic versus nonorganic). Extracts from organically produced shiitake contained the highest content of ergosterol, isoleucine and alanine. In conclusion, this work demonstrated that culture conditions influence the chemical profile of L. edodes as far as ergosterol and amino acids are concerned, which could improve nutrition and human health.
\end{abstract}

Keywords: Lentinus edodes; food health benefit; medicinal mushrooms; culture conditions

\section{Introduction}

Lentinus edodes (Berk.) Singer (Lentinula edodes (Berk.) Pegler, Marasmiaceae, Agaricomycetes) is an edible mushroom cultivated and marketed due to its nutritional and medicinal values [1-4]. The shiitake mushroom is appreciated for its unique fragrant taste; its high dietetic potential is valuable for health and its bioactive molecules explain its interest as medicinal mushroom [5-7]. Shiitake can be grown using various substrates and culture conditions [8,9]. Our work focused on the comparison of amino acids and ergosterol contents from L. edodes fruit bodies cultivated in organic or nonorganic growing conditions in the French region of Occitanie. 


\section{Materials and Methods}

\subsection{Mushroom Materials}

Shiitake fruit bodies were cultivated by three mushroom producers [9] in the French region of Occitanie using the strain Mycelia-3782 in various growing conditions (organic: producer B; nonorganic: producers A and C). Mycelia-3782 strain of L. edodes (Mycelia, Deinze, Belgium) was cultivated on sterilized substrate blocks of his own engineering (producer B) or provided from commercial substrate (producers A and C).

The L. edodes sporophores from producer A (Fontiès-d'Aude, France) grew on a mixture of wood chips and straw (nonorganic conditions; substrate of Eurosubstrat, Callac, France) with temperatures ranging from 10 to $20^{\circ} \mathrm{C}$ and $80 \%$ humidity.

The mushrooms generated by producer B (Saint-André-de-Lancize, France) were cultivated in the Cevennes National Park on organic sawdust of chestnut, wheat bran, and rye (organic conditions) with temperatures ranging from 18 to $21^{\circ} \mathrm{C}$ and $60-70 \%$ humidity.

The mushrooms from producer C (Saint-Bonnet-de-Salendrinque, France) grew on a mixture of wood chips, oak sawdust, and straw (nonorganic conditions, substrate of "Lentin de la buche" SA, Monétay-sur-Loire, France) and temperatures ranged from 15 to 17 ${ }^{\circ} \mathrm{C}$ and $100 \%$ humidity.

\subsection{Sample Preparation}

Five kilograms of L. edodes from each producer were cleaned, sliced, gauged, and carefully packaged in plastic bags and snap frozen. Then, they were lyophilized in a RP2V lyophilizer (Groupe Serail, Le Coudray Saint Germer, France).

\subsection{Extraction Conditions}

Sequential extraction (cyclohexane, chloroform, ethanol, water) under sonication was performed on freeze-dried fungal materials. First, $50 \mathrm{~g}$ of each lyophilized mushroom sample were crushed with a Thermomix Vorwerk crusher (Vorwerk, Wuppertal, Germany). Then, $5 \mathrm{~g}$ of crushed mushroom were placed in $50 \mathrm{~mL}$ cyclohexane, sonicated for $90 \mathrm{~min}$ at $30^{\circ} \mathrm{C}$, and then filtered using a Büchner device. The cyclohexanic filtrate was stored for subsequent evaporation procedure. Retentate was then submitted successively to extractions with chloroform $(50 \mathrm{~mL})$, ethanol $(50 \mathrm{~mL})$, and water $(50 \mathrm{~mL})$ under the same conditions.

\subsection{Quantification of Ergosterol}

Quantification of ergosterol was performed as previously described by Barreira et al. [10] using high performance liquid chromatography (Ultimate U3000 Thermo Fisher Scientific Inc., San Jose, CA, USA). The system was operated using Chromeleon software, version 7.0. Chromatographic separation was achieved on an ODS Hypersyl C18 column $(250 \mathrm{~mm} \times 4.6 \mathrm{~mm}, 5 \mu \mathrm{m}$, Thermo Fisher Scientific Inc., Waltham, MA, USA), with column temperature maintained at $30^{\circ} \mathrm{C}$. The mobile phase consisted of a mixture of methanol and acetonitrile (isocratic 30:70 during $30 \mathrm{~min}$, then methanol 100\% during $10 \mathrm{~min}$, flow rate: $1 \mathrm{~mL} / \mathrm{min})$. Furthermore, $20 \mu \mathrm{L}$ of the extracts $(5 \mathrm{mg} / \mathrm{mL})$ were analyzed. Ergosterol was quantified by comparison of the area of its peak with the calibration curve (250 $\mu \mathrm{g} / \mathrm{mL}, 62.5 \mu \mathrm{g} / \mathrm{mL}, 15.6 \mu \mathrm{g} / \mathrm{mL}$, and $3.9 \mu \mathrm{g} / \mathrm{mL}$ ) obtained from a commercial standard (Acros Organics, Thermo Fisher Scientific Inc., Waltham, MA, USA; $98 \%$ purity). The UVVis spectra were recorded in the $200-400 \mathrm{~nm}$ range and chromatograms were acquired at $280 \mathrm{~nm}$ for quantification of ergosterol. The results are expressed in $\mathrm{mg} / \mathrm{mg}$ of extract and in $\mathrm{mg} / 100 \mathrm{~g}$ of dry material.

\subsection{Quantification of Free Amino Acids}

Quantitative evaluation of amino acids was carried out for the ethanolic extracts using high performance thin layer chromatography (HPTLC) Camag Automatic TLC sampler using HPTLC Silica gel 60 glass plates (Merck, Kenilworth, NJ, USA) as stationary 
phase and butanol/acetic acid/water (3:1:1) as mobile phase; detection of amino acids was performed at $550 \mathrm{~nm}$ (Camag TLC scanner 3) after spraying ninhydrin reagent. Calibration curves were established with the amino acids standards (aspartic acid, glutamic acid, alanine, arginine, glycine, histidine, isoleucine, methionine, phenylalanine, serine, threonine, and valine; Sigma-Aldrich, Saint-Louis, Missouri, USA; 99\% purity) at $25 \mu \mathrm{g} / \mathrm{mL}$, $12.5 \mu \mathrm{g} / \mathrm{mL}, 6.25 \mu \mathrm{g} / \mathrm{mL}, 3.12 \mu \mathrm{g} / \mathrm{mL}$, and $0.75 \mu \mathrm{g} / \mathrm{mL}$. The ethanolic extracts were analyzed at $1 \mathrm{mg} / \mathrm{mL}$.

\section{Results}

\subsection{Ergosterol, a Provitamin of Vitamin $\mathrm{D}_{2}$}

Quantification of ergosterol was only made for cyclohexane, chloroform, and ethanol shiitake extracts from the three producers. Indeed, all aqueous extracts did not contain ergosterol (detection limit $0.001 \mathrm{mg} / \mathrm{mg}$ of extract).

Higher concentration was observed in the most apolar solvents, especially in cyclohexane extract of nonorganic producer $\mathrm{C}(\mathrm{C}>\mathrm{B}>\mathrm{A})$.

In terms of total amount of ergosterol, Table 1 shows that producer B $(478.21 \mathrm{mg} / 100$ $\mathrm{g}$ dry weight of shiitake) has a higher content than producer A $(294.43 \mathrm{mg} / 100 \mathrm{~g}$ of dry weight) and producer $C(341.29 \mathrm{mg} / 100 \mathrm{~g}$ of dry weight). Indeed, shiitake fruit bodies from organic producer $\mathrm{B}$ have the highest ergosterol content and thus it is an appreciated source of precursor of vitamin $\mathrm{D}_{2}$ (Table 1 ).

Table 1. Ergosterol concentration (mg/mg of shiitake extract, $n=3)$ and ergosterol content (mg/100 g dry weight of shiitake).

\begin{tabular}{cccc}
\hline Producers & Extracts & Ergosterol Concentration & Ergosterol Content \\
\hline & Cyclohexane & $0.169 \pm 0.012$ & \\
A & Chloroform & $0.095 \pm 0.006$ & 294.43 \\
& Ethanol & $0.001 \pm 0.001$ & \\
& Water & 0.001 & \multirow{2}{*}{478.21} \\
B & Cyclohexane & $0.183 \pm 0.016$ & \\
& Chloroform & $0.15 \pm 0.019$ & \\
& Ethanol & $0.002 \pm 0.001$ & 341.29 \\
& Water & 0.001 & \\
\hline
\end{tabular}

\subsection{Free Essential and Non Essential Amino Acids}

Ethanolic extracts of shiitake were investigated for twelve free amino acids. Compared to the retention factor of the standards, three free amino acids were identified and quantified following the scan of the HPTLC chromatoplates. These were two essential amino acids (valine and isoleucine) and a non-essential amino acid (alanine).

The highest value of the essential amino acid valine was reported for nonorganic producer $C(5.17 \mu \mathrm{g} / \mathrm{mg}$ of extract; Table 2$)$. The highest concentration of essential amino acid isoleucine was reported for organic producer B $(7.29 \mu \mathrm{g} / \mathrm{g}$ of extract).

The highest values of alanine (non-essential amino acid) were demonstrated for organic producer B and nonorganic producer A as $8.53 \mu \mathrm{g} / \mathrm{mg}$ and $8.21 \mu \mathrm{g} / \mathrm{g}$ of shiitake extracts, respectively. 
Table 2. Amino acids concentration $(\mu \mathrm{g} / \mathrm{mg}$ of shiitake ethanolic extract, $n=3)$.

\begin{tabular}{cccc}
\hline \multirow{2}{*}{ Ethanolic Extracts } & \multicolumn{3}{c}{ Amino Acids Concentration $(\boldsymbol{\mu g} / \mathbf{m g}$ of Extract) } \\
\cline { 2 - 4 } & Alanine & Valine & Isoleucine \\
\hline Producer A & $8.21 \pm 0.46$ & $3.77 \pm 0.28$ & $5.42 \pm 0.17$ \\
Producer B & $8.53 \pm 0.25$ & $3.71 \pm 0.15$ & $7.29 \pm 0.97$ \\
Producer C & $5.92 \pm 0.50$ & $5.17 \pm 0.60$ & $6.19 \pm 0.71$ \\
\hline
\end{tabular}

\section{Discussion}

It is difficult to compare the results that we obtained for ergosterol and amino acids contents from cultivated L. edodes fruit bodies (strain Mycelia-3782) in organic and nonorganic culture conditions with those previously reported based on different strains and culture conditions as well as various extraction methodologies [10-12].

Ergosterol content as $107.9 \mathrm{mg} / \mathrm{g}$ of fresh weight cultivated shiitake mushrooms produced in Sweden (unspecified strain, unspecified culture conditions) was reported in 2007 [13]. Later, ergosterol content was reported as $84.9 \mathrm{mg} / \mathrm{g}$ of fresh weight from commercially distributed shiitake in U.S. markets (unspecified strain, unspecified culture conditions) [14]. This year, ultraviolet irradiation was reported to increase the concentration of Vitamin $\mathrm{D}_{2}$ [15] and decrease the concentration of ergosterol in shiitake powder in an ethanolic suspension, but the authors did not release the exact value of the controls (around $5000 \mu \mathrm{g} / \mathrm{g}$ of dry weight of shiitake bought in a Chinese market, unspecified strain, unspecified culture conditions). A similar study [16] was previously carried out with shiitake fruit bodies purchased from a local farm in Thailand (unspecified strain or culture conditions; the ergosterol content was evaluated to be around $3.8 \mathrm{mg} / \mathrm{g}$ of dry weight). In these two last studies the ergosterol contents were comparable to ours.

Recently, the L. edodes strain WX1 (ACCC 50926) was investigated for amino acid contents based on five mushroom cultivation substrates prepared as follows [17]: control ( $80 \%$ oak sawdust; wheat bran $18 \%$; lime $1 \%$; saccharose $1 \%$ ), RS20 ( $20 \%$ rice straw; $60 \%$ oak sawdust; wheat bran 18\%; lime 1\%; saccharose 1\%), RS40 (40\% rice straw; $40 \%$ oak sawdust; wheat bran $18 \%$; lime $1 \%$; saccharose $1 \%$ ), RS60 (60\% rice straw; $20 \%$ oak sawdust; wheat bran $18 \%$; lime $1 \%$; saccharose $1 \%$ ), and RS80 ( $80 \%$ rice straw; wheat bran $18 \%$; lime $1 \%$; saccharose $1 \%$ ). The contents of total free amino acids varied from 16.29 to $24.59 \mathrm{mg} / \mathrm{g}$ of dry weight and the highest level of free amino acids was found in mushrooms cultivated from RS20 and RS40 [17]. The highest level of alanine $(3.38 \mathrm{mg} / \mathrm{g})$, valine $(0.55 \mathrm{mg} / \mathrm{g})$, and isoleucine $(0.22 \mathrm{mg} / \mathrm{g})$ were produced on RS20.

\section{Conclusions}

Our study focused on the chemical composition of L. edodes fruit bodies cultivated by nonorganic and organic mushroom professionals using the same strain. This work demonstrated that culture conditions of L. edodes influence the chemical profile of the harvested sporophores for the chemical constituents as ergosterol and free amino acids. Several shiitake strains and various growing substrates will need to be tested under both organic and nonorganic conditions to improve biosynthesis of those fungal chemical constituents; that could contribute to improving nutrition and human health.

Author Contributions: Conceptualization, S.M., F.F., and I.D.; methodology, S.M., M.V., and I.D.; validation, S.M., M.V., and I.D.; formal analysis, S.M.; investigation, I.D., S.M., and M.V.; writing original draft preparation, F.F., S.R., and S.M.; supervision, S.M. and F.F.; project administration, P.P., A.M., and F.F.; funding acquisition, P.P., A.M., and L.T. All authors have read and agreed to the published version of the manuscript.

Funding: This study was financially supported by the French Embassy in Guinea (Campus France).

Institutional Review Board Statement: Not applicable." Our studies did not involve humans or animals. We might also choose to exclude this statement because the study did not involve humans or animals. 
Informed Consent Statement: "Not applicable." for studies not involving humans.We might also choose to exclude this statement because the study did not involve humans.

Data Availability Statement: We choose to exclude this statement because the study did not report any data already published.

Acknowledgments: Thanks are extended to R. Loubet, C. Veenstra, and V. Lehnebach for supplying the fresh Lentinus edodes mushrooms and reporting cultivation methods.

Conflicts of Interest: The authors declare no conflict of interest.

\section{References}

1. Poucheret, P.; Fons, F.; Rapior, S. Biological and pharmacological activity of higher fungi: 20-Year retrospective analysis. Cryptogam. Mycol. 2014, 27, 311-333.

2. Diallo, I.; Alain, M.; Poucheret, P.; Sylvie, M.; Manon, V.; Traoré, L.; Rapior, S.; Fons, F. Lentinula edodes (Shiitake), an edible nutritional and medicinal mushroom: Health benefits and risks. In Non-Pharmacological Interventions: From Methodology to Evidence of Efficacy, Proceedings of the iCEPS Conference 2017, 5ème Édition., Montpellier, France, 18-20 May 2017; Univ Montpellier, Montpellier, pp. E9.

3. Gaitán-Hernández, R.; Zavaleta, M.A.B.; Aquino-Bolaños, E.N. Productivity, Physicochemical Changes, and Antioxidant Activity of Shiitake Culinary-Medicinal Mushroom Lentinus edodes (Agaricomycetes) Cultivated on Lignocellulosic Residues. Int. J. Med. Mushrooms 2017, 19, 1041-1052, doi:10.1615/intjmedmushrooms.2017024521.

4. Bernaś, E.; Jaworska, G.; Kmiecik, W. Storage and processing of edible mushrooms. Acta Sci. Pol. Technol. Aliment. 2006, 5, 5-23.

5. Mata, G.; Valdez, K.; Mendoza, R.; Trigos, A. HS/GC-MS analyzed chemical composition of the aroma of fruiting bodies of two species of genus Lentinus (Higher Basidiomycetes). Int. J. Med. Mushrooms 2014, 16, 477-484, doi:10.1615/intjmedmushrooms.v16.i5.60.

6. Mattila, P.; Salo-Väänänen, P.; Könkö, K.; Aro, H.; Jalava, T. Basic Composition and Amino Acid Contents of Mushrooms Cultivated in Finland. J. Agric. Food Chem. 2002, 50, 6419-6422, doi:10.1021/jf020608m.

7. Rathore, H.; Prasad, S.; Sharma, S. Mushroom nutraceuticals for improved nutrition and better human health: A review. Pharma Nutr. 2017, 5, 35-46, doi:10.1016/j.phanu.2017.02.001.

8. Chakravarty, B. Trends in mushroom cultivation and breeding. AJAE 2011, 2, 102-109.

9. Diallo, I.; Boudard, F.; Morel, S.; Vitou, M.; Guzman, C.; Saint, N.; Michel, A.; Rapior, S.R.; Traoré, L.; Poucheret, P.; et al. Antioxidant and Anti-Inflammatory Potential of Shiitake Culinary-Medicinal Mushroom, Lentinus edodes (Agaricomycetes), Sporophores from Various Culture Conditions. Int. J. Med. Mushrooms 2020, 22, 535-546, doi:10.1615/intjmedmushrooms.2020034864.

10. Barreira, J.C.M.; Oliveira, M.B.P.P.; Ferreira, I.C. Development of a Novel Methodology for the Analysis of Ergosterol in Mushrooms. Food Anal. Methods 2013, 7, 217-223, doi:10.1007/s12161-013-9621-9.

11. Balbi, M.E.; Fabeni, F.; Lazinski, L.M.; Melo, A.C.S.; Souza, H.F. Nutritional analysis and amino acid profile of shiitake mushroom (Lentinus edodes, Agaricaceae). Visão Acadêmica 2013, 14, 49-60, doi:10.5380/acd.v14i4.35107.

12. Park, Y.-A.; Bak, W.-C.; Ka, K.-H.; Koo, C.-D. Comparative analysis of amino acid content of Lentinula edodes, a new variety of shiitake mushroom, in 'Poongnyunko'. J. Mushroom 2017, 15, 31-37, doi:10.14480/JM.2017.15.1.31.

13. Teichmann, A.; Dutta, P.C.; Staffas, A.; Jägerstad, M. Sterol and vitamin D2 concentrations in cultivated and wild grown mushrooms: Effects of UV irradiation. LWT 2007, 40, 815-822, doi:10.1016/j.lwt.2006.04.003.

14. Phillips, K.M.; Ruggio, D.M.; Horst, R.L.; Minor, B.; Simon, R.R.; Feeney, M.J.; Byrdwell, W.C.; Haytowitz, D.B. Vitamin D and Sterol Composition of 10 Types of Mushrooms from Retail Suppliers in the United States. J. Agric. Food Chem. 2011, 59, 78417853, doi:10.1021/jf104246z.

15. Hu, D.; Chen, W.; Li, X.; Yue, T.; Zhang, Z.; Feng, Z.; Li, C.; Bu, X.; Li, Q.X.; Hu, C.Y.; et al. Ultraviolet Irradiation Increased the Concentration of Vitamin D2 and Decreased the Concentration of Ergosterol in Shiitake Mushroom (Lentinus edodes) and Oyster Mushroom (Pleurotus ostreatus) Powder in Ethanol Suspension. ACS Omega 2020, 5, 7361-7368, doi:10.1021/acsomega.9b04321.

16. Banlangsawan, N.; Sanoamuang, N. Effect of UV-B irradiation on contents of ergosterol, vitamin D2, vitamin B1 and vitamin B2 in Thai edible mushrooms. Chiang Mai J. Sci. 2016, 43, 45-53.

17. Gao, S.; Huang, Z.; Feng, X.; Bian, Y.; Huang, W.; Liu, Y. Bioconversion of rice straw agro-residues by Lentinula edodes and evaluation of non-volatile taste compounds in mushrooms. Sci. Rep. 2020, 10, 1814-1818, doi:10.1038/s41598-020-58778-x. 